The classes are again divided into tertiles according to their relative rank at graduation and the percentage of $e$.'s, g.'s, $m$.'s, and $u$.'s won by each tertile in the management of children, instruction, and attention to the details of school business in their work as temporary substitutes, permanent substitutes, and teachers are presented in order. The table compares 17090 markings of principals, 10704 of which were on the service as temporary substitutes of 295 graduates, 5585 on the work of the same group as permanent substitutes, and 801 on the services of 144 graduates (Classes of January, 1911, and June, 1911, and January, 1912) as appointed teachers. The temporary substitutes' service covered a period of 12197 days, the permanent substitutes' 1975 months, and appointed teachers' 196 terms. It will be noted that the percentage of $e$.'s and g.'s is very high amounting to $85 \%$ or more of all the markings, even of the lowest third of the classes.

There are two respects in particular in which the correlation does not hold in this table, namely, management and attention to detail of school business as teachers. Several causes may be mentioned which will explain the lack of correlation in this particular in this table. Furst, these markings represent only one and one-half mark per teacher. This means that these marks cover only the first term of teaching for one half and a second term for the other half of the group. Second, no instruction is given in the management of children and attention to details of school business in the College. Third, the young teacher, facing the numerous situations, naturally emphasizes those things she can do best and that is the instruction. Fourth, management and attention to details are more or less matters of routine that the teacher must learn from experience and which she would naturally find irksome until they are routinized. They do not become routinized in the first term. Fifth, and finally, the correlation does hold in later teaching as indicated by data which are not yet in shape for presentation.

The degree of correlation indicated in this study seems to lead to the unmistakable conclusion that scholarship, measured by the standards of the schools, will indicate success in teaching in after life in spite of the numerous exceptions to the rule that lead so often to the erroneous statement that there is no correlation between scholarship and teaching ability. Whether this same degree of correlation prevails in other vocations, we make no attempt to say.

Principal Harris Teachers College,

E. George Payne. St. Louis, Missouri.

\title{
PROVISION FOR A POST-SENIOR YEAR FOR HIGH SCHOOL SCIENCE TEACHERS
}

A post-senior year has been provided at the Carnegie Institute of Technology as a part of its professional requirement for those fitting themselves to be teachers of the physical sciences in high schools. About a quarter of the time in this fifth year is devoted to supervised teaching. This practice is given in the institution. A limited number of post-senior students will be paid sufficient for this work to relieve them of the financial burden of the extra year in their course. The plan is somewhat analogous to the hospital service of an interne in the medical profession.

Graduates of other colleges who have taken their degrees in general science and carried some work in psychology or education can usually qualify for the post- 
senior year without taking extra courses. At present the outline of the training course provides only for teachers of physics and chemistry, although it is planned later to extend the work to preparation for teaching other sciences. The basis is also laid in education and psychology for advancement to administrative positions since promotion often occurs in this field to a prncipalship or executive work for those showing the necessary personal traits.

By means of the fifth year of required work the prospective teacher is carried considerably farther in the intensive courses in his particular subject than is possible at colleges which prepare high school teachers with a shorter course. It is believed that this extra training in his science, coupled with the technique of teaching, will equip the science teacher so that he can bring to the high school students the inspiration of the man who knows more than his text. For teaching in college the student is expected to plan for additional graduate years.

Since a large portion of the five-year science teachers' course parallels the fouryear preparation for the scientific research option, the graduate is also prepared for positions in government or industrial research laboratories. This research preparation is planned to afford better training for many positions than the regular engineering or liberal arts courses. All general science students study French and German and continue their major science with special instruction in theoretical subjects and laboratory practice to enable them at the time of graduation to undertake immediately many of the problems assigned to physicists or chemists, thus laying a substantial foundation for post-graduate work.

In the bulletin announcing these courses the student is cautioned as to the personal qualifications he should possess. This official description for the vocational guidance of prospective college students is so unusual that it will bear quotation.

"To succeed in the Science Course and in Research, a student should possess unusual ability in Mathematics, Physics, and Chemistry. He must have an interest not only in the practical applications of his major subject, but also in theoretical study and investigation, and should be a student by inclination. He must be patient and painstakingly thorough. If he is also onginal he should be very successful.

"A student planning to take the teachers' option of this course should, in addition to the above qualifications, possess an attractive personality, teaching ability, and the faculty of clear and forceful expression. He will be more successful as a teacher if he possesses habits of openmindedness, geniality, fairness, and the ability to put himself at the other person's point of view. He should be interested most of all in young men; and to him enthussasm for his subject and for teaching that subject should outweigh the greater financial attractions of other professions."

Carnegie Institute of Technology,

J. B. MiNER.

Pittsburgh. 